\title{
Resistance of three implant-abutment interfaces to fatigue testing
}

\author{
Cleide Gisele RIBEIRO'1, Maria Luiza Cabral MAIA², Susanne S. SCHERRER ${ }^{3}$, Antonio Carlos CARDOSO ${ }^{4}$, \\ H. W. Anselm WISKOTT ${ }^{5}$
}

1- DDS, MSc, PhD, Graduate student, Department of Dental Implantology, University of Santa Catarina, Florianópolis, SC, Brazil.
2- DDS, Graduate student, Department of Prosthodontics-Biomaterials, University of Geneva, Geneva, Switzerland.
3- DDS, PhD, Senior lecturer, Department of Prosthodontics-Biomaterials, University of Geneva, Geneva, Switzerland.
4- DDS, MSc, PhD, Head Professor, Department of Dental Implantology, University of Santa Catarina, Florianópolis, SC, Brazil.
5- DDS, MSc, PhD, Senior lecturer, Department of Prosthodontics-Biomaterials, University of Geneva, Geneva, Switzerland.

Corresponding address: Cleide Gisele Ribeiro - Avenida Barão do Rio Branco, 2406/506 e 507 - Centro - 36010-011 - Juiz de Fora - Minas Gerais - Brazil - Phone: +55-32-3216-6246 - Fax: +55-32-9109-2678 - e-mail: cleidegr@yahoo.com.br

Received: May 25, 2009 - Modification: April 27, 2009 - Accepted: October 26, 2010

\section{ABSTRACT}

\begin{abstract}
$T^{\mathrm{T}}$ he design and retentive properties of implant-abutment connectors affect the mechanical resistance of implants. A number of studies have been carried out to compare the efficacy of connecting mechanisms between abutment and fixture. Objectives: The aims of this study were: 1) to compare 3 implant-abutment interfaces (external hexagon, internal hexagon and cone-in-cone) regarding the fatigue resistance of the prosthetic screw, 2) to evaluate the corresponding mode of failure, and 3) to compare the results of this study with data obtained in previous studies on Nobel Biocare and Straumann connectors. Materials and Methods: In order to duplicate the alternating and multivectorial intraoral loading pattern, the specimens were submitted to the rotating cantilever beam test. The implants, abutments and restoration analogs were spun around their longitudinal axes while a perpendicular force was applied to the external end. The objective was to determine the force level at which $50 \%$ of the specimens survived $10^{6}$ load cycles. The mean force levels at which $50 \%$ failed and the corresponding 95\% confidence intervals were determined using the staircase procedure. Results: The external hexagon interface presented better than the cone-in-cone and internal hexagon interfaces. There was no significant difference between the conein-cone and internal hex interfaces. Conclusion: Although internal connections present a more favorable design, this study did not show any advantage in terms of strength. The external hexagon connector used in this study yielded similar results to those obtained in a previous study with Nobel Biocare and Straumann systems. However, the internal connections (cone-in-cone and internal hexagon) were mechanically inferior compared to previous results.
\end{abstract}

Key words: Dental implants. Fatigue. Prosthesis failure.

\section{INTRODUCTION}

Dental implantology has revolutionized the treatment for edentulous and partially edentulous patients, and successful implant integration has been well documented for patients with those clinical conditions. With the high rate of implant success for edentulous individuals, the concept of osseointegration and implant therapy has flourished as a predictable treatment modality ${ }^{10}$.

Clinical observations have indicated that the major causes of implant failure are (a) deficient osseointegration, (b) complications of the neighboring soft tissues (peri-mucositis and periimplantitis) and (c) mechanical complications ${ }^{13}$. Among the biomechanical problems, screw loosening, abutment rotation, and abutment fracture are the major issues ${ }^{15,28}$. In a prospective multicenter investigation, Henry, et al.12 (1996) evaluated 92 patients with 107 implants and found that the problems most frequently experienced during the first year were related to lose screws. The two mechanisms involved in screw loosening are: excessive bending (plastic deformation that 
takes place when a load larger than the yield strength of the screw is applied) and settling (when external loads applied to the screw interface create micromotion between both surfaces). As the mating surfaces wear, they "settle" closer together ${ }^{15}$. The factors that contribute to screw instability are: misfit of the prosthesis, insufficient tightening force, screw settling, mechanical overload, and mismatch in screw material and design².

A number of studies have been conducted to compare the efficacy of different connecting mechanisms securing the abutment to the implant head $^{16}$. The design of the implant-to-abutment mating surface and the retentive properties of the screw joints affect the mechanical resistance of the implant-abutment complex ${ }^{3,20}$. The implantabutment connection is also influenced by factors such as component fit, machining accuracy, saliva contamination and screw preload ${ }^{4}$.

Current designs are derived from two basic designs: the "butt-joint", consisting of 2 parallel flat contacting surfaces ${ }^{3}$, and the internal "conein-cone" design. The latter has been introduced in the ITI implant system (Institute Straumann AG, Waldenburg, Basel, Switzerland) and offered a sound, stable, and self-locking interface ${ }^{29}$. Recent studies have indicated a potential mechanical advantage of conical connectors over butt-joint designs $^{20}$. Indeed, the mechanics of the ITI cone-in-cone ${ }^{20}$ resulted in lower incidences of mechanical complications, specifically abutment screw loosening and fracture, in comparison with those reported for butt-joint implants ${ }^{23,25}$. With few exceptions, most of the long-term clinical data on implant performance involve external hexagons. This is primarily the result of their extensive use, the broad number of prescribed clinical applications, the level of complications reported, and the resulting efforts to find solutions (specific torque application to abutment screws) ${ }^{3}$. Industry surveys have shown that external hex implants still dominate the European market ${ }^{18}$.

Fatigue is a progressive, localized and permanent structural damage that occurs in a material subjected to repeated or fluctuating strains. Experimentally, three modes of loading may be used to duplicate fatigue failures: direct axial loading (the specimen is submitted to a uniform stress through its cross-section), plane-bending (the majority of the specimen is subjected to a uniform bending stress) and rotating-beam loading (the specimen is rotation-symmetric and is subjected to dead-weight loading while swivel bearings permit rotation) ${ }^{24}$. In order to duplicate the multivectorial force pattern of the mouth, a laboratory test has been developed by Wiskott, et al. ${ }^{34}$ (2004) using the rotating beam principle. The test consists in spinning a specimen while holding it at one end and loading it at the protruding end. The samples are thus subjected to a 360-degree field of transverse tensile and compressive force vectors. Actuator-driven fatigue testing systems are unable to reproduce the complex force patterns that are active clinically. Hence data obtained using rotational fatigue testing have a superior pertinence relative to single-axis testing designs ${ }^{32-33}$.

To overcome some of the inherent design limitations of the external hex connector, a variety of alternative connections have been developed. The goals of this study were: (1) to evaluate the fatigue resistance of 3 implant-abutment connectors (external hexagon, internal hexagon and conein-cone) analyzing the prosthetic screw; 2) to determine their failure modes; and (3) to compare the obtained results with previous data generated from Nobel Biocare-Replace and Straumann-ITI connectors.

\section{MATERIAL AND METHODS}

Three geometries of implant-abutment interfaces were evaluated. Thirty implants $(4.0 \mathrm{~mm}$ diameter and $13 \mathrm{~mm}$ long) of each connector type were connected to Micro-unit abutments (Conexão Sistemas de Prótese, Arujá, SP, Brazil) and torqued to $30 \mathrm{Ncm}$ using a calibrated torque controller. The Micro-unit abutments are industrially machined prosthetic components that are intended for use in fixed partial and complete implantsupported dentures at all sulcus depths and for all platforms. They were designed to provide versatility while optimizing the esthetics of multiple unit, screw retained, restorations. Therefore, the sole differences between groups were the variations in the interface geometry between the implant head and the Micro-unit abutment. The cone-in-cone Micro-unit abutment used in this study presents an internal modification (internal hexagon), which is located at the bottom of the cone to allow the angular repositioning of the abutments. The groups were set up as follows: group A (external hex implant+micro-unit abutment+restoration analog); group B (cone-in-cone implant+micro-unit abutment+restoration analog); group C (internal hex implant+micro-unit abutment+restoration analog).

In order to duplicate the mouth's multivectorial force pattern, the specimens (implant, abutment and restoration analog) were configured as rotating cantilever beams (Figure 1). The rotating beam principle demands that a concentric arrangement be established between all the components. One end of the test specimen is clamped into a collet and rotated, while a perpendicular force is applied to the other end via a ball bearing. This perpendicular force submits the specimens to alternating sinusoidal 
tension-compression stresses which, depending on the magnitude of the load applied, cause breakage of the components within a predetermined number of cycles. The fatigue resistance of the connectors is expressed as the force level at which $50 \%$ of the specimens survive $10^{6}$ load cycles without breakage and $50 \%$ fail.

\section{Restoration analog}

The Micro-unit abutments used were 1-mmhigh collar platforms. To allow valid comparisons with previous data, the restoration analog was 20 $\mathrm{mm}$ in length. This provided a $11.3 \mathrm{~mm}$ distance between the midplane of the ball bearing and the emergence of the implant from the collet. The torque recommended by the manufacturer was $20 \mathrm{Ncm}$ for the abutment screw and $20 \mathrm{Ncm}$ for the prosthetic screw. At this torque, however, both screws loosened during the course of the experiment. It was therefore decided to torque the abutment screw to $30 \mathrm{Ncm}$ and the prosthetic screw to $25 \mathrm{Ncm}$ to induce failure by screw breakage and not by screw loosening.

\section{Experimental procedure and data analysis}

The three implant-abutment interfaces were evaluated regarding their fatigue resistance at $10^{6}$ cycles (an arbitrarily set number whose theoretical and practical basis has been previously explained) ${ }^{33}$.
The experimental procedure required that a number of specimens be tested in sequence. To this effect, the specimens were loaded via the ball bearing and spun at $1.000 \mathrm{rpm}(16.7 \mathrm{~Hz})$. After $10^{6}$ cycles, the experimenter checked whether the specimen was intact or whether it had broken. If it was intact, the next specimen was loaded at the previous magnitude plus $5 \mathrm{~N}$. The same force ( 5 $\mathrm{N}$ ) was subtracted from the former load magnitude if the previous specimen had failed. This leads to the characteristic up-and-down pattern of runouts and failures that characterizes the staircase procedure. After suitable arrangement of the data, the mean $\mathrm{F}_{50}$ (at which $50 \%$ of the samples failed and $50 \%$ ran out) and the standard deviation were calculated (Table 1). When applying the staircase procedure, the examiner must set an appropriate force increment (or decrement) $\left(\mathrm{F}_{\text {incr. }}\right)-5 \mathrm{~N}$ in the present test series. If it is too large, the test looses its discriminating potential. In this experiment, $F_{\text {incr }}$ was taken from previous studies ${ }^{32,34}$.

During testing, the results were graphically charted as in Figure 2. After all tests had been completed, they were arranged as shown in Table 1. Taking A and B from Table 1, F50 was calculated as

$$
\mathrm{F}_{50}=\mathrm{F}_{0}+{ }_{\text {Fincr }} \quad\left[\frac{\mathrm{A}}{n} \pm \frac{1}{2}\right]
$$

with: + if the test is based on run-outs,

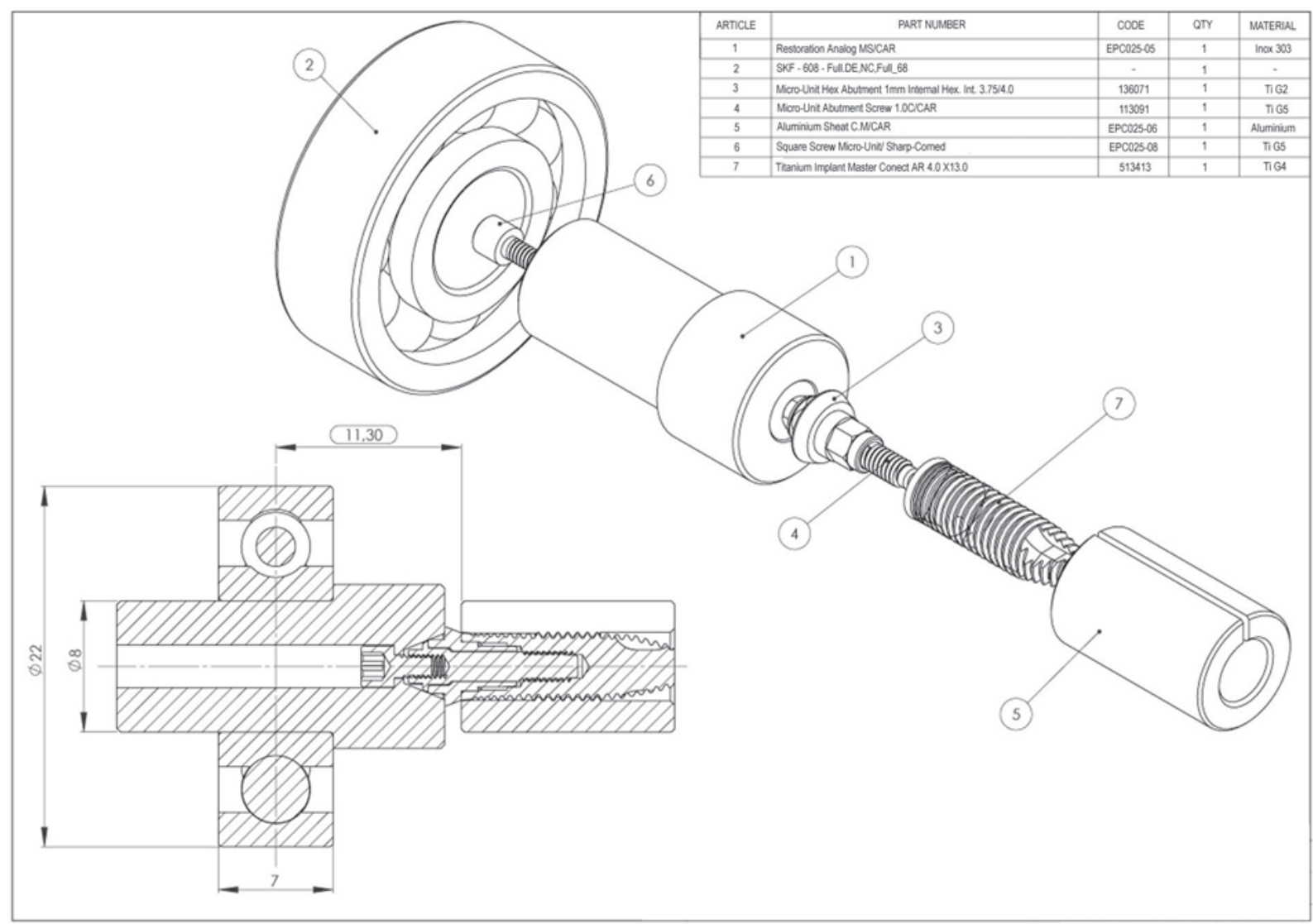

Figure 1- Schematic drawing of the sample (internal hexagon interface- group C) 

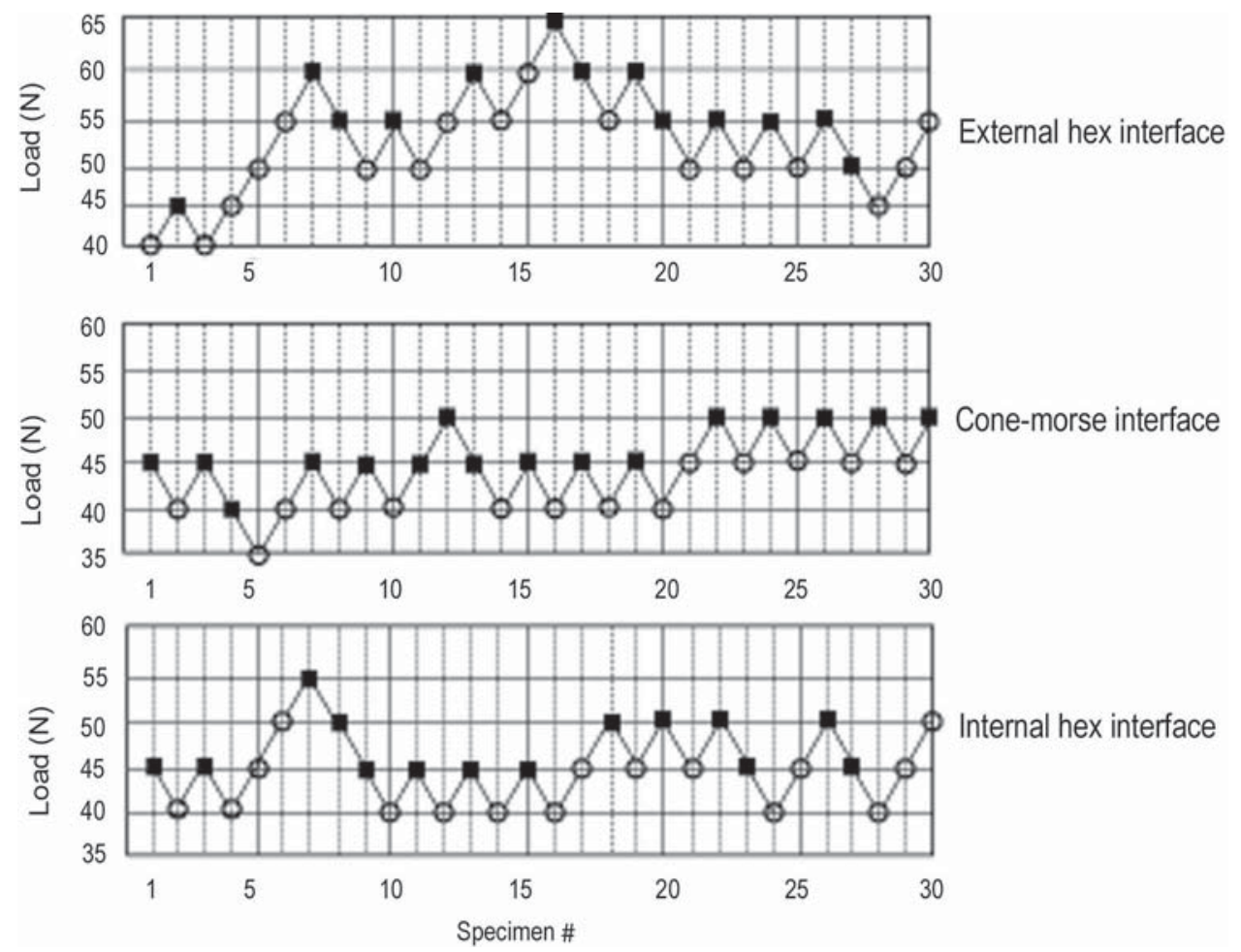

Figure 2- Staircase data for the implant abutment interfaces analyzed in the study

Table 1- Example of data arrangement for staircase analyses (external hexagon interface)

\begin{tabular}{ccccc}
\hline $\begin{array}{c}\text { Applied forces in } \\
\text { newtons }\end{array}$ & Force level (i) & \# of failures $\left(\mathbf{n}^{\prime}\right)$ & $\mathbf{i} \mathbf{n}^{\mathbf{1}}$ & $\mathbf{i}^{\mathbf{2}} \mathbf{n}^{\mathbf{1}}$ \\
\hline 65 & 5 & 1 & 5 & 25 \\
60 & 4 & 4 & 16 & 64 \\
55 & 3 & 6 & 18 & 54 \\
50 & 2 & 1 & 2 & 4 \\
45 & 1 & 1 & 1 & 1 \\
40 & 0 & 0 & 0 & $\mathrm{~B}=148$ \\
\hline
\end{tabular}

$n=\Sigma n^{\prime}, A=\Sigma$ in', $B=\Sigma i^{2} n^{\prime}$

- if the test is based on failures

Whenever the number of run-outs and failures differed, data analysis was based on the least frequent event.

The corresponding standard deviation was taken as:

$1.62_{\text {Fincr }}\left[\frac{n B-A 2}{n 2}+0.029\right]$ if $\frac{n B-A 2}{n 2} \geq 0.3$ and

$0.53_{\text {Fincr }}\left[\frac{n B-A 2}{n 2}+0.029\right]$ if $\frac{n B-A 2}{n 2} \leq 0.3$

Where $\mathrm{F}_{50}$ was the mean force level at which $50 \%$ of specimens ran-out and $50 \%$ failed; $F_{0}$ was the lowest load level at which failure occurred; $F_{\text {incr }}$ was the chosen force increments or decrement, that is, $5 \mathrm{~N} ; \mathrm{n}=\Sigma \mathrm{n}^{\mathrm{i}}$ ( $\mathrm{n}^{\mathrm{i}}$ : the number of failures of each load level) (see table 1 ); $A=\Sigma$ in (i being the load level) and $\mathrm{B}=\Sigma \mathrm{i}^{2} \mathrm{n}^{\mathrm{i}}$.

To assess whether the $\mathrm{F}_{50}$ 's of each group were significantly different, the means were fitted with 95\% confidence intervals using a method described by Collins ${ }^{9}$ (1993). Means with overlapping intervals were considered equivalent.

Stereomicroscope examination and scanning electron microscopy (SEM)

Ten prosthetic screws of each interface were randomly selected and evaluated using 
a stereomicroscope (Wild M3Z, Heerbrugg, Switzerland) to inspect thread wear, defects and the fractured surfaces at low magnification. Stereomicroscopy is often used to conduct preliminary observations of fractured components. After this evaluation, 3 samples of fractured screws of each interface were gold-sputtered and examined with a scanning electron microscope (Philips XL Series - XL 20; Philips, Eindhoven, The Netherlands).

\section{RESULTS}

The fatigue resistance for each connector expressed as the mean force level at which $50 \%$ of the samples survived $10^{6}$ cycles and $50 \%$ failed $\left(F_{50}\right)$ is shown in Table 2, which also details each mean's 95\% CI. Statistically, the external hexagon interface presented superior result compared to the conical and internal hexagon interfaces. There was no significant difference between the conical and internal hex interfaces.

Analysis of the fractured screws stereomicroscopy and SEM revealed that the mode and the region of fracture were the same for 24 of the 30 screws evaluated (fracture of the threaded part - Figures $3,4)$. Six screws presented damages in the last two threads but no fracture (Figure 5). Fatigue

Table 2- Fatigue resistance of the connectors subjected to the rotating-bending test

\begin{tabular}{lcccc}
\hline & F50 & SD & Upper & Lower \\
\hline External hex interface & 53.5 & 7.80 & 49.5 & 57.5 \\
Cone-in-cone interface & 44.0 & 2.49 & 42.3 & 45.7 \\
Internal hex interface & 45.0 & 3.40 & 43.1 & 46.9 \\
\hline
\end{tabular}

$F_{50}=$ mean failure level (force level at which $50 \%$ of the samples survive and $50 \%$ fail before $10^{6}$ cycles). When the interfaces with overlapping Cls were combined, 1 group was identified: group A - external hex interface. SD= standard deviation

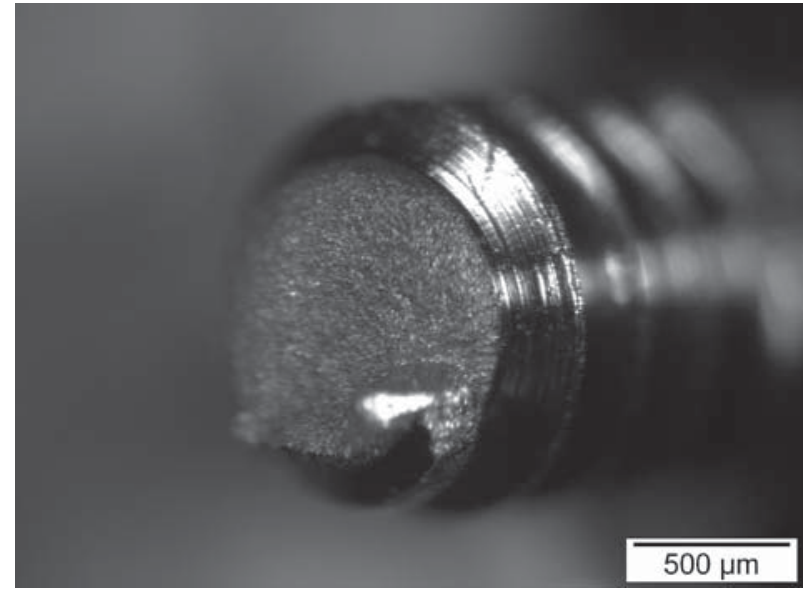

Figure 3- Stereomicroscope image of the prosthetic screw at the fractured surface

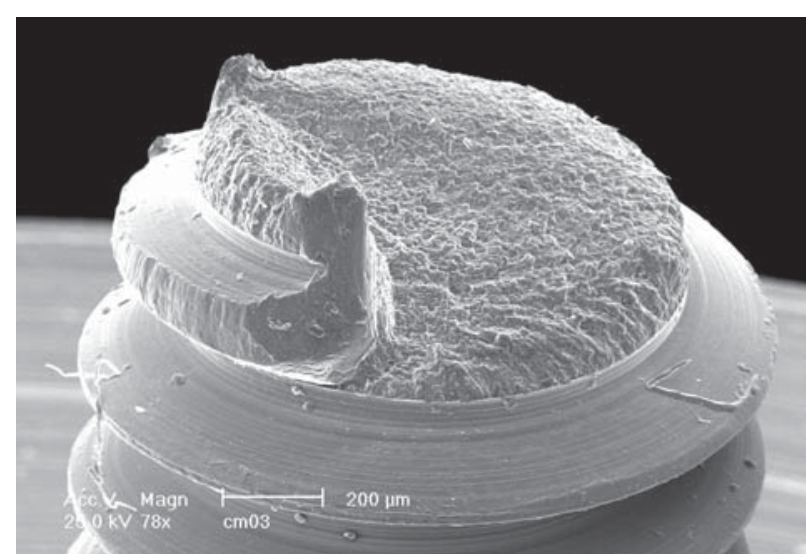

Figure 4- Scanning electron microscopy (SEM) micrograph of the screw abutment at the fractured surface

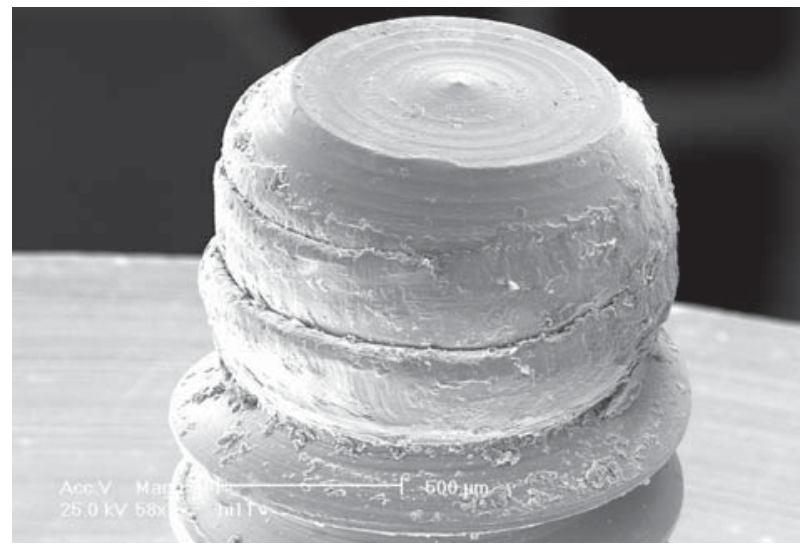

Figure 5-Scanning electron microscopy (SEM) micrograph demonstrating damages in the screw threads without fracture

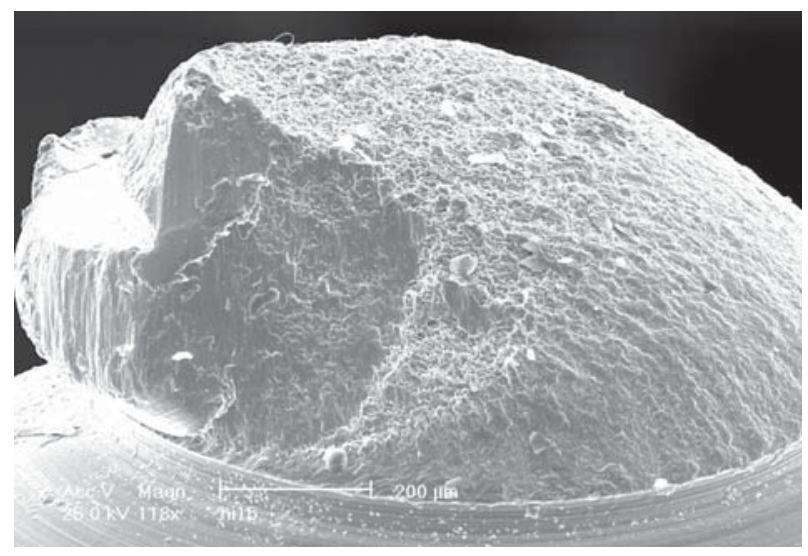

Figure 6-Scanning electron microscopy (SEM) micrograph showing fatigue striations 

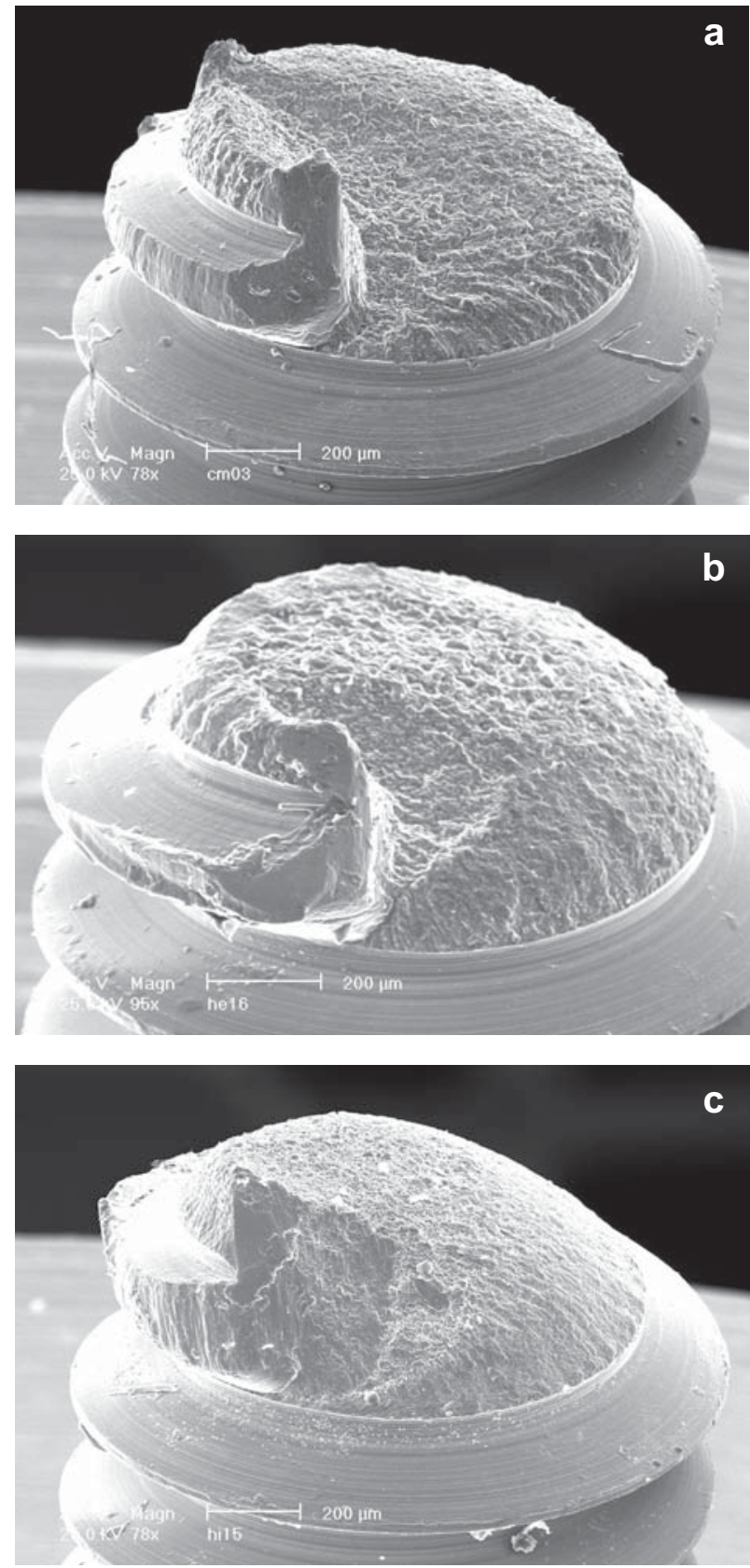

Figure 7- Scanning electron microscopy (SEM) micrograph images of prosthetic screws showing the same mode of fracture to all the types of implant-abutment interfaces (acone-in-cone; b- external hexagon and c- internal hexagon)

striations were seen on the SEM micrographs (Figure 6). Such striations are an absolute indication of fatigue failure. "Overload" or fast fracture zone, that is, the portions of the components where final catastrophic failure occurred were also seen. The surface structure of this zone was similar for all groups (Figures 7A-C).

\section{DISCUSSION}

The effect of connector design on the mechanical resistance of a dental implant screw joint is still fraught with uncertainties. This is demonstrated by the numerous configurations available in today's market. Several systems are in clinical use, most notably the external hexagon, the internal hexagon and the tapered joints. According to Binon ${ }^{3}$ (2000), contemporary implant systems are configured with about 20 different implant/abutment interface geometries.

Each implant-abutment interface has its pros and cons. According to Maeda, et al. ${ }^{16}$ (2006), the external hex interface has advantages such as suitability for the two stage method, provision of an anti-rotation mechanism, retrievability and compatibility among different systems ${ }^{6}$. The external hex interface provides more versatility for the laboratory technician in solving problems related to emergence profile and esthetics, since the technician is able to bring the porcelain of a porcelain-fused-to-gold crown closer to the implant interface ${ }^{6}$. However, increased screw loosening, component fracture, and difficulty in seating abutments in deep subgingival tissues are problems commonly experienced with external hexagon connectors ${ }^{29}$.

Regarding the internal hex system, according to Maeda, et al. ${ }^{16}$ (2006), its advantages are: ease in abutment connection, suitability for one stage implant installation, higher stability and suitability for single-tooth restoration, higher resistance to lateral loads due to the lower centre of rotation and better force distribution ${ }^{6}$. A systematic review conducted by Theoharidou, et al. ${ }^{31}$ (2008) demonstrated stable abutment screw connections for internal-connection implants as well for externalconnection implants with improved screw materials (altering the screw alloys and their surfaces) and preload. Tapered joint connections with a conical interface have advantages of better sealing capacity in closing the micro-gap on top of those in an internal hex system. Most in vitro studies have demonstrated that internal connections are more stable mechanically than external flat connections ${ }^{16,20}$. The general focus is clearly on deep internal connections, in which the screw takes little or no load and provides intimate contact with the implants walls to resist micromovement ${ }^{3}$.

The present data are in agreement with those of Piermatti, et al.22 (2006), who reported inferior results for the internal hex connections when compared to external connections. Steinebrunner, et al. $^{26}$ (2008) evaluated the influence of longterm dynamic loading on the fracture strength of different implant-abutment connectors. External hex connections yielded better results compared to internal hex connections. Also, the internal tube-and-tube connections with a cam indexing system obtained the superior results with regard to longevity and fracture strength. Former research 
was able to show that there is a direct correlation between the amount of misfit of the components and screw loosening ${ }^{4}$. Binon and $\mathrm{McHugh}^{4}$ (1996) pointed towards manufacturing tolerances as a reason for the screw loosening of the prefabricated parts and requested manufacturers to improve the fit of their implant components.

Preload protects the screw from breakage during cyclic loading. If the joint is compressed, preload will be lost, the screw and the interface are subjected to plastic deformation and the joint may separate ${ }^{35}$. The optimum preload force recommended for an implant screw is $60-80 \%$ of the yield strength of the material from which the screw is machined. At stresses at or beyond yield, the screw will function in its plastic deformation zone with resulting loss of preload and inefficient function. Conversely, stresses within the elastic region of the material are the most appropriate to resist the separation forces induced during occlusal loading ${ }^{21}$. Thus, the greater the clamping force (preload), the tighter the clamped joint. However, preload values should not be too high and should be within the elastic domain, else retaining screws may yield or break under repeated functional bite forces $^{1}$. The torque used in this study was $30 \mathrm{Ncm}$ in the abutment screw and $25 \mathrm{Ncm}$ in the prosthetic screw. SEM analysis of screws tightened to 25 $\mathrm{Ncm}$ and to $40 \mathrm{Ncm}$ demonstrated no damages in the screw morphology thereby indicating that the torque applied was below the elastic limit of the material. The yield strength and the breakage strength of screws are not commonly reported by manufacturers.

The literature provides an abundance of studies that analyzed the fatigue resistance of dental implants and prosthetic components. However, there was no standardization of the applied forces $300 \mathrm{~N}^{1,35} ; 100-150 \mathrm{~N}^{7} ; 10-250 \mathrm{~N}^{17} ; 20-200 \mathrm{~N}^{8} ; 100-$ $450 \mathrm{~N}^{11} ; 50 \mathrm{~N}^{27} ; 120 \mathrm{~N}^{26}$ and in the mode of loading (angle of load application) and simple (fatigue only) or combined (fatigue plus monotonic load). The loading frequencies were different also. The present study was carried out using comparable implant diameters, identical abutments and levers therefore rendering intergroup comparisons possible. The results demonstrated that the fatigue strength of the external hex interface used in this study was of the same magnitude as the Nobel Biocare Replace Select, multi-unit abutment and the Straumann ITI, standard abutment. The internal connections though (conical and internal hexagon) revealed inferior results compared to the previous data 32,34 .

The prosthetic screw that connects the fixed dental prosthesis to the abutment is intended as the weak link, that is, in case of occlusal overload, it is designed to break first and thus protect the implant and the bone from damage due to excessive stresses $^{5,23}$. This is supported by the finding that the incidence of abutment screw and implant fracture is much lower than that of prosthetic screw loosening or fracturing 5,19 . Conversely, according to Sutter, et al. ${ }^{29}$ (1993), in the two-stage system it is the abutment screw that most frequently fractures. This apparent incrongruity of the more massive abutment screw failing before the smaller occlusal screw might be explained by simple mechanics. In a two-stage system, the abutment screw secures the abutment to the implant. This interface is subjected to a higher level of stress because it is located near the alveolar crest, that is, where the applied lever is greatest. The abutment screw therefore, is subjected to much greater forces than the occlusal screw when the force vectors are nonaxial in nature. It is thus more susceptible to fatigue failure, although it is a more massive structure $^{30}$. The present study confirms that the prosthetic screw fails more frequently than the abutment screw and failure varies according to the type of interface analyzed.

\section{CONCLUSIONS}

Within the limitation of this study, the following conclusions can be drawn: 1 . This study demonstrated the superior fatigue resistance of external hex interface. There was no significant difference between the conical and internal hex interfaces. Probably, the quality of the surface machining of the flat-to-flat mating surfaces (mainly, the machining accuracy of the screw and thread) determined the superior resistance of the connector; 2; The mode and region of fracture in prosthetic screws observed in this study suggested that failure of these screws occurred by fatigue (presence of fatigue striations) and involved the threaded part; 3 . The present tests demonstrated that the fatigue strength of the external hex interface used in this study was of comparable strength as that determined in a previous study on Nobel Biocare and Straumann implants when similar abutments and level torque were used. It is important to emphasize that the prosthetic screw used in this study was designed specifically to support a higher torque $(25 \mathrm{Ncm})$ than the conventional torque used for this screw $(10 \mathrm{Ncm})$. In addition, the micro-unit abutment received a higher torque than the one recommended by the manufacturer; 4. The internal connections (conein-cone and internal hexagon) had inferior results compared to those found in previous results. Internal connections require accurate machining and tolerances and the reason for the present results may be a lack of precision of the components that allowed micromovement at the connector interface. 


\section{ACKNOWLEDGMENTS}

Our gratitude is expressed to Conexão Sistemas de Prótese (Arujá, SP, Brazil) for designing and machining the implants and components used in this study.

\section{REFERENCES}

1- Al Jabbari YS, Fournelle R, Ziebert G, Toth J, Iacopino AM. Mechanical behavior and failure analysis of prosthetic retaining screws after long-term use in vivo. Part 4: Failure analysis of 10 fractured retaining screws retrieved from three patients. J Prosthodont. 2008;17:201-10.

2- Al-Turki LE, Chai J, Lautenschlager EP, Hutten MC. Changes in prosthetic screw stability because of misfit of implant-supported prostheses. Int J Prosthodont. 2002;15:38-42.

3- Binon PP. Implants and components: entering the new millennium. Int J Oral Maxillofac Implants. 2000;15:76-94.

4- Binon PP, McHugh MJ. The effect of eliminating implant/ abutment rotational misfit on screw joint stability. Int J Prosthodont. 1996;9:511-9.

5- Brägger U. Technical failures and complications related to prosthetic components of implant systems and different types of suprastructures. In: Lang NP, Karring T, Lindhe J, eds. Proceedings of the $3^{\text {rd }}$ European Workshop on Periodontology. Berlin: Quintessence; 1999. p. 304-32.

6- Carr BT, Dersh DA, Harrison WR, Kinsel RP. When contemplating treatment involving endosseous implants, what clinical and laboratory factors most significantly affect your choice of an implant system? Int J Oral Maxillofac Implants. 2001;16:123-7. 7- Cehreli M, Duyck J, De Cooman M, Puers R, Naert I. Implant design and interface force transfer. A photoelastic and strain-gauge analysis. Clin Oral Implants Res. 2004;15:249-57.

8- Cibirka RM, Nelson SK, Lang BR, Rueggeberg FA. Examination of the implant-abutment interface after fatigue testing. J Prosthet Dent. 2001;85:268-75.

9- Collins J. Failure of materials in mechanical design: analysis, prediction, prevention. New York: Wiley-Interscience; 1993.

10- Ding TA, Woody RD, Higginbottom FL, Miller BH. Evaluation of the ITI Morse taper implant/abutment design with an internal modification. Int J Oral Maxillofac Implants. 2003;18:865-72.

11- Gehrke P, Dhom G, Brunner J, Wolf D, Degidi M, Piattelli A. Zirconium implant abutments: fracture strength and influence of cyclic loading on retaining-screw loosening. Quintessence Int. 2006;37:19-26

12- Henry PJ, Laney WR, Jemt T, Harris D, Krogh PH, Polizzi G, et al. Osseointegrated implants for single-tooth replacement: a prospective 5 -year multicenter study. Int J Oral Maxillofac Implants. 1996;11:450-5.

13- Huang HM, Tsai CM, Chang CC, Lin CT, Lee SY. Evaluation of loading conditions on fatigue-failed implants by fracture surface analysis. Int J Oral Maxillofac Implants. 2005;20:854-9.

14- Jörnéus $L$, Jemt $T$, Carlsson L. Loads and designs of screw joints for single crowns supported by osseointegrated implants. Int J Oral Maxillofac Implants. 1992;7:353-9.

15- Kano SC, Binon PP, Curtis DA. A classification system to measure the implant-abutment microgap. Int J Oral Maxillofac Implants. 2007;22:879-85.
16- Maeda $Y$, Satoh T, Sogo M. In vitro differences of stress concentrations for internal and external hex implant-abutment connections: a short communication. J Oral Rehabil. 2006;33:758.

17- Meng JC, Everts JE, Qian F, Gratton DG. Influence of connection geometry on dynamic micromotion at the implant-abutment interface. Int J Prosthodont. 2007;20:623-5.

18- Millennium Research Group. European markets for dental implants and final abutments 2004: executive summary. Implant Dent. 2004;13:193-6.

19- Möllersten $L$, Lockowandt $P$, Lindén LA. Comparison of strength and failure mode of seven implant systems: an in vitro test. J Prosthet Dent. 1997;78:582-91.

20- Norton MR. An in vitro evaluation of the strength of an internal conical interface compared to a butt joint interface in implant design. Clin Oral Implants Res. 1997;8:290-8.

21- Patterson EA, Johns RB. Theoretical analysis of the fatigue life of fixture screws in osseointegrated dental implants. Int J Oral Maxillofac Implants. 1992; 7:26-33.

22- Piermatti J, Yousef $\mathrm{H}$, Luke A, Mahevich $\mathrm{R}$, Weiner $\mathrm{S}$. An in vitro analysis of implant screw torque loss with external hex and internal connection implant systems. Implant Dent. 2006;15:427-35.

23- Rangert $B$, Jemt $T$, Jörneus $L$. Forces and moments on Branemark implants. Int J Oral Maxillofac Implants. 1989;4:241-7. 24- Ritchie R. Fatigue testing. In: ASM International, ed. ASM Handbook - Mechanical testing and evaluation. Ohio: ASM International; 2000. p. 688-9.

25- Schwarz MS. Mechanical complications of dental implants. Clin Oral Implants Res. 2000;11:156-8.

26- Steinebrunner L, Wolfart S, Ludwig K, Kern M. Implantabutment interface design affects fatigue and fracture strength of implants. Clin Oral Implants Res. 2008;19:1276-84.

27- Strub JR, Gerds T. Fracture strength and failure mode of five different single-tooth implant-abutment combinations. Int J Prosthodont. 2003;16:167-71.

28- Stüker RA, Teixeira ER, Beck JC, Costa NP. Preload and torque removal evaluation of three different abutment screws for single standing implant restorations. J Appl Oral Sci. 2008;16:55-8.

29- Sutter F, Weber J, Sorensen J. The new restorative concept of the ITI dental implant system: design and engineering. Int J Periodont Rest Dent. 1993;13:409-31.

30- Taylor TD. Prosthodontic problems and limitations associated with osseointegration. J Prosthet Dent. 1998;79:74-8.

31- Theoharidou A, Petridis HP, Tzannas K, Garefis P. Abutment screw loosening in single-implant restorations: a systematic review. Int J Oral Maxillofac Implants. 2008;23:681-90.

32- Wiskott HW, Jaquet R, Scherrer SS, Belser UC. Resistance of internal-connection implant connectors under rotational fatigue loading. Int J Oral Maxillofac Implants. 2007;22:249-57.

33- Wiskott HW, Nicholls JI, Belser UC. Fatigue resistance of soldered joints: a methodological study. Dent Mater. 1994;10:21520.

34- Wiskott HW, Pavone AF, Scherrer SS, Renevey RR, Belser UC. Resistance of ITI implant connectors to multivectorial fatigue load application. Int J Prosthodont. 2004;17:672-9.

35- Yousef $H$, Luke A, Ricci J, Weiner S. Analysis of changes in implant screws subject to occlusal loading: a preliminary analysis. Implant Dent. 2005;14:378-82. 